\title{
Avaliação da permeação transcutânea de formulações cosméticas contendo cafeína e Centella asiatica por meio de sistema de difusão vertical
}

\section{Evaluation of transcutaneous permeation of cosmetic formulations containing caffeine and Centella asiatica through the vertical diffusion system}

Bruna dos Santos Kensy, Karina Schettert Kerschnera, Regis Augusto Norbert Deuschle, Gabriela Bonfanti Azzolin, Dinara Hansen Costa, Viviane Cecília Kessler Nunes Deuschle

Como citar este artigo:

KENSY, BRUNA S.; KERSCHNERA KARINA S.; DEUSCHLE, REGIS AUCUSTO N.; AZZOLIN, GABRIELA B.; COSTA, DINARA H.; DEUSCHLE, VIVIANE CECÍLIA K. N.; Avaliação da permeação transcutânea de formulações cosméticas contendo cafeína e Centella asiatica por meio de sistema de difusão vertical. Revista Saúde (Sta. Maria). 202 1; 47 (1).

\section{Autor correspondente:}

Nome: Viviane Cecilia Kessler

Nunes Deusche

Telefone: (55) 332। 1500

E-mail: vdeuschle@unicruz.edu.br Formação Profissional: Formada em Farmácia pela Universidade de Cruz Alta (UNICRUZ) que fica na cidade de Cruz Alta, RS, Brasil.

Filiação Institucional: Universidade de Cruz Alta

Endereco para correspondência:

Rua: Universidade de Cruz Alta,

Centro de Ciências da Saúde

e Agrárias. Rodovia Municipal Jacob Della Méa

Bairro: Distrito Parada Benito

Cidade: Cruz Alta

Estado: Rio Grande do Sul

CEP: 98020290

Data de Submissão:

30/01/2021

Data de aceite:

|9/02/202 |

Conflito de Interesse: Não há conflito de interesse

\section{(cc) BY-NC-ND}

\section{RESUMO}

Objetivo: Avaliar a cedência, a permeação e a retenção da cafeína e do extrato de Centella asiatica de formulações cosméticas. Métodos: Foram desenvolvidas três formulações em gel contendo: $1 \%$ de cafeína (F1); $1 \%$ de cafeína e $3 \%$ de extrato glicólico de Centella asiática (F2) e uma somente com $3 \%$ de extrato glicólico de Centella asiática (F3). Para avaliação da cedência, permeação e retenção, foram utilizadas células de difusão vertical tipo Franz. Os ensaios foram conduzidos com e sem o uso do ultrassom. 0 teor de cafeína foi quantificado por espectrofotometria e a presença do extrato de Centella asiatica foi avaliada por cromatografia em camada delgada. Resultados: Observou-se que houve cedência dos ativos em todas as formulações, com e sem o uso do ultrassom. A permeação ocorreu somente com o uso do ultrassom. A retenção foi menor em F2 do que em F1 com o uso do ultrassom e, consequentemente, a permeação foi maior. Sem o uso do ultrassom, houve uma maior retenção dos ativos emtodas as formulações, que podem ainda ser permeada ao longo do tempo. A Centella asiatica foi capaz de ultrapassar a membrana de acetato de celulose (cedência), permear a pele suína e ficar retida no estrato córneo. Consideraçãoes finais: Conclui-se que a associação de cafeína com extrato glicólico de Centella asiatica parece ser uma combinação eficaz para o tratamento do fibro edema geloide, uma vez que apresentou resultados satisfatórios para todos os ensaios realizados.

PALAVRAS-CHAVE: Lipólise; Celulite; Terapia por ultrassom; Fonoforese; Estética.

\section{ABSTRACT}

Objective: To evaluate the yield, permeation and retention of caffeine and Centella asiatica extract from cosmetic formulations. Methods: Three gel formulations containing: 1\% caffeine (F1); $1 \%$ caffeine and $3 \%$ glycolic extract of Centella asiatica (F2) and one with only $3 \%$ glycolic extract of Centella asiatica (F3). For the assessment of yield, permeation and retention, Franz-type vertical diffusion cells were used. The tests were conducted with and without the use of ultrasound. The caffeine content was quantified by spectrophotometry and the presence of Centella asiatica extract was evaluated by thin layer chromatography. Results: It was observed that there assets release in all formulations, with and without the use of ultrasound. Permeation occurred only with the use of ultrasound. Retention was lower in F2 than in F1 with the use of ultrasound and, consequently, permeation was greater. Without the use of ultrasound, there was a greater retention of assets in all formulations, which can still be permeated over time. Centella asiatica was able migration through the cellulose acetate membrane (release), permeate the porcine skin and stay retained in the stratum corneum. Conclusion: It is concluded that the association of caffeine with glycolic extract of Centella asiatica seems to be an effective combination for the treatment of Fibro Edema Geloide, since it presented satisfactory results for all the tests performed.

KEYWORDS: Lipolysis; Cellulite; Ultrasonic Therapy; Phonophoresis; Esthetics. 


\section{INTRODUÇÃO}

O fibro edema gelóide (FEG), também conhecido como celulite, é ocasionado por uma alteração na hipoderme. Na celulite, os adipócitos aumentam de tamanho, comprimindo os vasos sanguíneos do tecido adiposo e consequentemente gerando um processo inflamatório, onde uma barreira fibrosa se forma ao redor das células adiposas. Alguns fatores podem contribuir para o FEG, como hábitos alimentares, hereditariedade, sedentarismo, estresse, hormônios como 0 estrogênio, por exemplo, e gênero. ${ }^{1,2}$

Com isso, diversos produtos cosméticos são desenvolvidos com o objetivo de tratar essa disfunção estética. Associados à mudanças de estilo de vida e tratamentos estéticos, essas formulações são capazes de melhorar o aspecto da pele no $\mathrm{FEG}^{2}$. Existem muitas formulações comercializadas para o tratamento do FEG, tanto para uso profissional como para home care. A maioria das formulações apresenta entre os seus ativos cosméticos a cafeína e a Centella asiatica. $^{3}$

A cafeína, pertencente à classe das metilxantinas, é utilizada como uma substância ativa capaz de promover a lipólise nos adipócitos, sendo amplamente utilizada no tratamento do FEG. Seu mecanismo de ação está associado com a estimulação dos receptores agonistas ( $\beta$-adrenérgicos) presentes na membrana da célula adiposa, promovendo assim a lipólise e redução da espessura da hipoderme e do volume dos adipócitos. ${ }^{4,5,6}$

A Centella asiatica é uma planta composta por triterpenos, como o asiaticosídeo, madecassosídeo, ácido madecássico e ácido asiático. É capaz de reestruturar o colágeno, acelerando a integração e o metabolismo da lisina e da prolina, aminoácidos essenciais para a estrutura do mesmo. Sua ação também está voltada para a redução de edema, favorecendo a microcirculação e auxiliando no tratamento do FEG ${ }^{7,8,9}$

Entretanto, a pele é uma barreira efetiva na proteção contra agentes externos, dificultando a penetração e permeação dos ativos através da mesma, sendo que muitos ficam retidos na camada córnea, não entrando em contato com as camadas mais profundas da pele. As propriedades dos ativos e dos veículos influenciam na difusão das substâncias através da pele e consequentemente, na eficácia e qualidade dos cosméticos. ${ }^{10,11}$

Por isso, algumas técnicas são utilizadas para facilitar a permeação das substâncias através da pele, como por exemplo, a utilização de promotores físicos de absorção. A fonoforese é uma técnica que usa o aquecimento e a energia do ultrassom para provocar mudanças estruturais nas camadas superficiais da pele, aumentando assim a permeabilidade dos ativos. As propriedades de barreira da pele são restauradas em um determinado período de tempo. 11,12,13

Para avaliar a capacidade de permeação das substâncias ativas e fármacos através da pele são necessários estudos que caracterizem este processo. A célula de difusão vertical tipo Franz é um método in vitro utilizada para este fim, onde utilizam-se membranas artificiais, como a membrana de acetado de celulose, ou biológicas, como pele de suínos. Esta célula possui um compartimento doador, onde é adicionada a formulação e outro receptor, preenchido por 
uma solução receptora. A membrana é empregada entre os dois compartimentos. Por meio dessa técnica, é possível avaliar a cedência da substância ativa do veículo, a retenção na camada córnea e a permeação para as camadas mais profundas da pele..$^{12,14,15}$

Na prática da estética, as formulações contendo cafeína e Centella asiatica são amplamente utilizadas. Vários estudos foram desenvolvidos baseados na permeação e efeito lipolítico da cafeína, mas não há relatos na literatura científica de estudos envolvendo a Centella asiatica de forma combinada com esse ativo. Neste contexto, o presente estudo teve por objetivo avaliar a cedência, a retenção e permeação cutânea de formulações cosméticas constituídas por cafeína e extrato de Centella asiatica, de forma isolada e combinada, por meio de sistema de difusão vertical.

\section{MATERIAIS E MÉTODO}

\section{Desenvolvimento das formulações}

As formulações foram preparadas em gel Carbopol (veículo) contendo $1 \%$ de cafeína e 3\% de extrato glicólico de Centella asiatica. Na Tabela 1 encontram-se a composição e denominação das formulações.

A cafeína foi previamente solubilizada em água, com auxílio de benzoato de sódio, na proporção de 1:1 em relação a cafeína. Essa solução foi adicionada ao gel de carbopol, previamente preparado. O extrato glicólico de Centella asiatica foi obtido comercialmente (Fagron $®)$.

Tabela 1. Denominação e composição das formulações utilizadas.

\begin{tabular}{ll}
\hline Nome da Formulação & Composição \\
\hline Formulação 1 (F1) & Gel + cafeína 1\% \\
Formulação 2 (F2) & Gel + cafeína 1\% + extrato de Centella asiatica 3\% \\
Formulação 3 (F3) & Gel + extrato de Centella asiatica 3\% \\
\hline
\end{tabular}

Fonte: Autor, 2019

\section{Delineamento do estudo}

Trata-se de um estudo experimental, conduzido com e sem o uso do ultrassom para promover a fonoforese, a partir de célula de difusão vertical tipo Franz fabricado por Góes Vidros Especiais (Porto Alegre, Rio Grande do Sul, Brasil). Foi utilizado um aparelho de ultrassom Sonopulse da marca Ibramed® (São Paulo, Brasil), operando na faixa de 3 $\mathrm{MHz}$, com área de radiação específica (ERA) de $3,5 \mathrm{~cm}^{2}$, no modo pulsado, com frequência de $16 \mathrm{~Hz}$, ciclo ativo de $50 \%$, intensidade de 0,8 w/ $/ \mathrm{cm}^{2}$, com tempo total de aplicação de 4 minutos. Os ensaios foram realizados da seguinte forma: cedência - com e sem ultrassom (membrana de acetato de celulose); permeação - com e sem ultrassom (pele suína); 
retenção - com e sem ultrassom (pele suína). Os ensaios sem o uso do ultrassom foram conduzidos em 30 minutos, 1 e 2 horas. Os ensaios com o uso do ultrassom foram conduzidos por 4 minutos, levando em consideração o mínimo de 1 minuto de aplicação para cada centímetro quadrado da ERA do equipamento.

\section{Análise da cedência do veículo}

As análises de liberação da cafeína e saponinas triterpênicas da Centella asiatica foram realizadas nas formulações utilizando-se uma célula de difusão vertical tipo Franz, com solução receptora constituída de tampão fosfato ( $\mathrm{pH} 7,2$ ), contendo uma membrana de acetato de celulose (porosidade de 0,45 $\mu \mathrm{m}$ e área de $7,06 \mathrm{~cm}^{2}$ ) com a finalidade de separar o compartimento doador do receptor, ou seja, formar uma barreira não interferente a um fluido denominado receptor. A célula de difusão foi introduzida em banho de ultrassom a $37^{\circ} \mathrm{C}$, simulando a temperatura corporal. Em contato com a membrana foram adicionadas as formulações. Na avaliação da liberação, foram realizadas análises em alíquotas retiradas da célula de difusão nos seguintes tempos: 30 minutos, 1 e 2 horas, para a verificação da presença das substâncias ativas na solução receptora, por meio de espectrofotometria e cromatografia em camada delgada. As análises foram realizadas em triplicata. ${ }^{13,16}$

\section{Análise da permeação e retenção cutânea}

A permeação in vitro da cafeína e saponinas triterpênicas da Centella asiatica foi realizada em célula de difusão vertical tipo Franz, com solução receptora constituída de tampão fosfato $(\mathrm{pH} \mathrm{7,2),} \mathrm{porém} \mathrm{contendo} \mathrm{a} \mathrm{pele} \mathrm{suína,} \mathrm{que}$ foi utilizada por possuir características que simulam a pele humana. ${ }^{17}$ Esse ensaio foi conduzido com e sem 0 uso do ultrassom.

Os fragmentos de pele suína foram retirados da célula de difusão vertical após o término do ensaio e recortadas adequadamente, para a realização do ensaio de retenção de substância ativa no estrato córneo. O excesso da formulação foi lavado com água deionizada e álcool etílico. As amostras foram reduzidas em pequenos fragmentos e transferidas para balão volumétrico e imersas em água deionizada e álcool etílico absoluto 99\%, na proporção de 1:1 e, após, foram levadas para banho de ultrassom por 40 minutos para favorecer a liberação das substâncias ativas. Foram retiradas alíquotas da solução, as quais foram analisadas por método espectrofotométrico (cafeína) e por cromatografia em camada delgada (CCD) (Centella asiatica). ${ }^{12}$

\section{Determinação da concentração da cafeína}

A cafeína foi identificada Espectrofotômetro Digital de Luz - UV-Visível (Modelo IL-592) no comprimento de onda de $273 \mathrm{~nm}$, conforme metodologia descrita por Li, Berger e Hartland. ${ }^{18}$ Para a determinação da concentração da cafeína 
(Fagron®) foi preparada uma curva analítica nas seguintes concentrações: 5, 10, 25, 50 e $75 \mathrm{mcg} / \mathrm{mL}$, diluídas em água destilada. Como branco foi utilizado água destilada. A equação linear para a curva de analítica foi: $y=0,0393 x+0,0802$; $\mathrm{R} 2=0,9919$.

\section{Determinação qualitativa da presença de saponinas triterpênicas da Centella asiatica}

A presença de saponinas triterpênicas foi determinada por Cromatografia em Camada Delgada (CCD) de acordo com o método descrito por Wagner e Bladt ${ }^{19}$ com modificações. A fase estacionária consistiu de uma placa de sílicagel F254. A fase móvel foi constituída pelo seguinte sistema eluente: clorofórmio: ácido acético glacial: metanol: água (64:32:12:8, V/V/V/V). Após a eluição, os resultados foram analisados em luz UV (254 e 365 nm) e visível utilizando como revelador a vanilina sulfúrica.

\section{Análise estatística}

Os resultados foram expressos como média \pm desvio padrão (DP). Todos os dados foram avaliados por análise de variância (ANOVA) seguida de Teste de Tukey, quando necessário, e Teste t de Student. Valores de p menores que 0,05 foram considerados significativos.

\section{RESULTADO}

Os resultados da cedência da cafeína sem a aplicação do ultrassom US foram analisados nos tempos de 30 minutos, 1 hora e 2 horas e encontram-se descritos na Tabela 2.

Tabela 2. Cedência da cafeína nas formulações 1 e 2 sem o uso do ultrassom, analisada por espectrofotometria.

\begin{tabular}{lll}
\hline Formulações/Tempo & F1 $(\mathrm{mcg} / \mathrm{mL} \pm \mathrm{DP})$ & $\mathbf{F 2}(\mathrm{mcg} / \mathrm{mL} \pm \mathrm{DP})$ \\
\hline $\mathbf{3 0}$ min. & $0,1 \pm 0,02^{\mathrm{a}}$ & $1,28 \pm 0,005$ \\
$\mathbf{1}$ hora & $1,18 \pm 0,07^{\mathrm{b}}$ & $1,31 \pm 0,11^{\mathrm{a}}$ \\
$\mathbf{2}$ horas & $1,19 \pm 0,06$ & $2,26 \pm 0,13^{\mathrm{b}}$ \\
\hline
\end{tabular}

Os resultados foram expressos como a média \pm desvio padrão (DP) de três determinações. As diferentes letras indicam diferença significativa $(p>0,05)$. 
A Figura 1 mostra os resultados da cedência da cafeína, nas formulações F1 e F2, com o uso do ultrassom.

Figura 1. Cedência da cafeína nas formulações 1 e 2 com o uso do ultrassom, analisada por espectrofotometria.

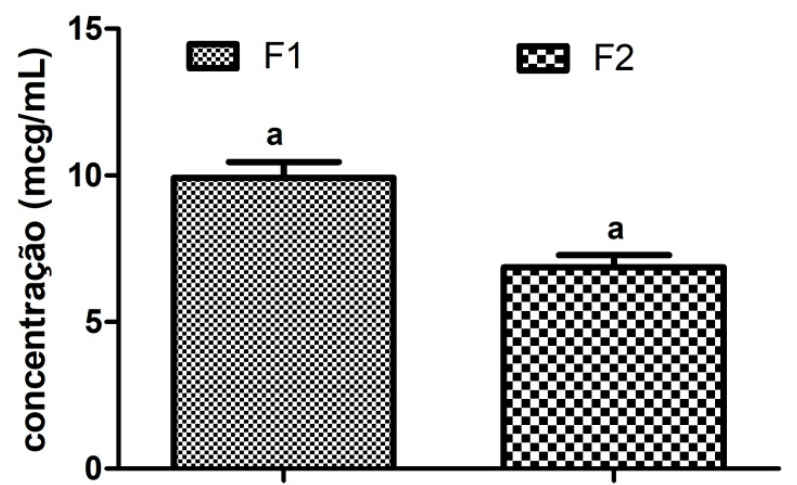

Formulações

Os resultados foram expressos como a média \pm DP de três determinações. As letras iguais indicam diferença significativa $(p>0,05)$.

Os resultados referentes à permeação da cafeína utilizando pele de porco e com a aplicação do ultrassom encontram-se na Figura 2. Não houve permeação da cafeína sem o uso do ultrassom.

Figura 2. Concentração permeada da cafeína nas Formulações 1 e 2 com exposição ao ultrassom em pele de porco

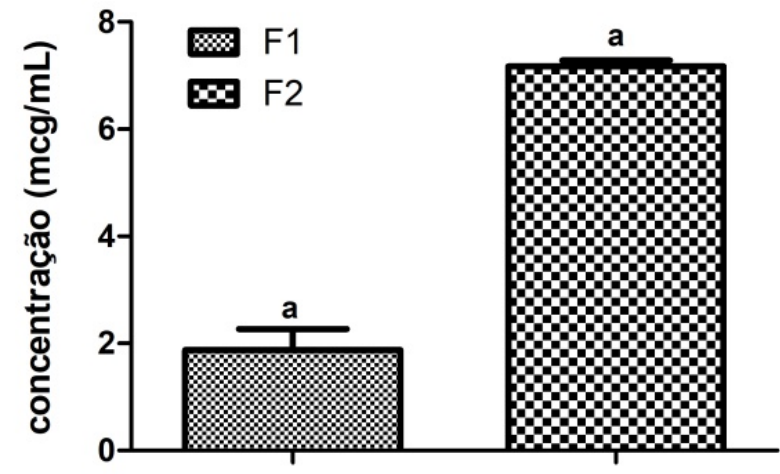

Formulações

Os resultados foram expressos como a média \pm DP de três determinações. As letras iguais indicam diferença significativa $(p>0,05)$. 
Em relação à retenção da cafeína no estrato córneo, os resultados obtidos estão demonstrados na Figura 3.

Figura 3. Retenção de cafeína nas Formulações 1 e 2 com e sem exposição ao ultrassom em pele de porco

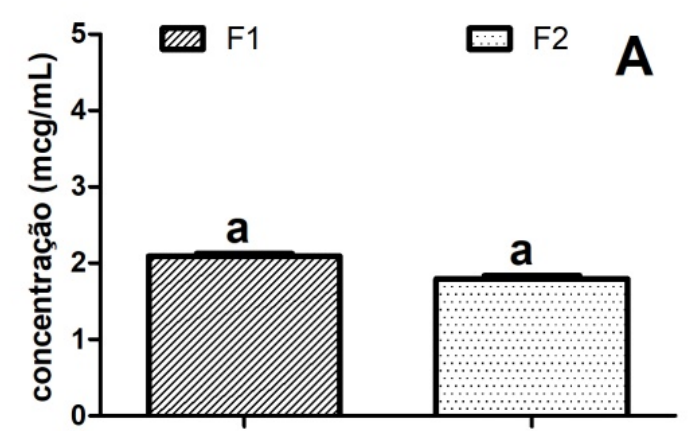

Formulações

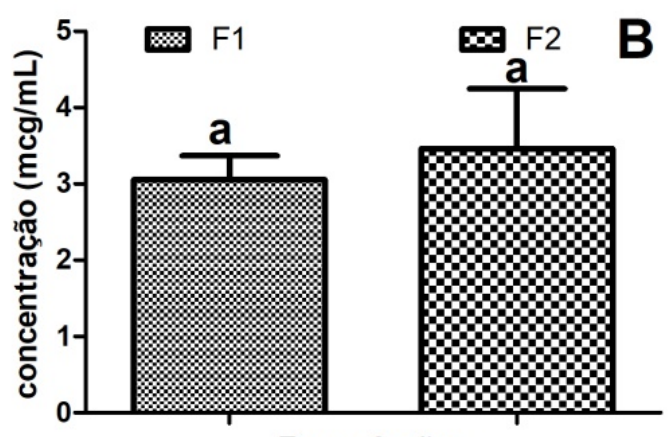

Formulações

Os resultados foram expressos como a média \pm DP de três determinações. As letras iguais indicam diferença significativa $(p>0,05)$.

A: com uso de ultrassom; B: sem uso de ultrassom.

A Tabela 3 traz os resultados referentes à cedência, permeação e retenção das saponinas triterpênicas da Centella asiatica, para determinação da presença desse ativo na pele.

Tabela 3. Resultado qualitativo para saponinas triterpênicas da Centella asiatica por meio de cromatografia em camada delgada.

\begin{tabular}{lll}
\hline Formulações & F2 & F3 \\
\hline Cedência 30 min & + & + \\
Cedência $1 \mathrm{~h}$ & + & + \\
Cedência $2 \mathrm{~h}$ & + & + \\
Cedência com US* & + & + \\
Permeação & + & + \\
Permeação com US & ++ & ++ \\
Retenção & + & + \\
Retenção com US & + & + \\
\hline
\end{tabular}

Resultado + significa resultado positivo com presença de mancha.

++ significa resultado positivo com presença de mancha de coloração intensa, de acordo com análise visual.

*Os ensaios com ultrassom foram realizados durante 4 minutos.

\section{DISCUSSÃO}

Para que as substâncias ativas atinjam a superfície da pele, precisam ser liberadas do veículo e, com isso, as propriedades físico-químicas dos princípios ativos e dos ingredientes que fazem parte da formulação podem interferir 
na capacidade de cedência. Após a liberação, podem ficar retidas no estrato córneo da epiderme ou permear até as camadas mais profundas da pele. . $2,20,21^{2}$

Com isso, a fonoforese é uma técnica que permite a permeação de substâncias ativas presentes em cosméticos para as camadas mais profundas da pele, com o uso do ultrassom, de forma segura e indolor. ${ }^{22}$

Nossos resultados demonstram que houve a cedência da cafeína das formulações. Observa-se que nas duas formulações (F1 e F2) a cafeína foi liberada do veículo, penetrando através da membrana de acetato de celulose e sendo quantificada na solução receptora da célula de difusão (Tabela 2). Os resultados demonstram que a concentração da cafeína em ambas as formulações foi aumentando ao longo das 2 horas de experimento. Contudo, em todos os tempos, o teor de cafeína em F2 foi maior que F1. Isso pode ter ocorrido pela presença do extrato glicólico de Centella asiatica em F2, o que reduz a viscosidade da formulação, permitindo um maior fluxo das substâncias ativas do veículo para a membrana. Já com o uso do ultrassom (Figura 1), a liberação da cafeína foi maior em F1 do que em F2 e, nesse caso, infere-se que a presença da Centella asiatica pode ter influenciado esse resultado. Ainda, com o uso do equipamento, a concentração foi maior do que sem o uso do mesmo.

A Figura 2 demonstra os resultados da concentração permeada em pele de porco com exposição ao ultrassom, para efeito de fonoforese. Observa-se que houve permeação da cafeína na membrana suína após a exposição a 4 minutos de ultrassom. Ao comparar F1 com F2, nota-se que a concentração permeada da cafeína foi maior na formulação 2. Isso pode ter ocorrido devido a presença do extrato glicólico de Centella asiatica na formulação, o que pode ter potencializado a penetração da cafeína, uma vez que atua na microcirculação sanguínea. Além disso, sabe-se que o glicerol (álcool) atua como um promotor químico de permeação, melhorando a hidratação da pele, a partição das moléculas dos ativos ou aumentando a sua solubilidade. ${ }^{11}$ Com isso, a presença do glicerol no extrato de Centela asiatica pode ter contribuído com uma maior difusão da cafeína na pele.

A cafeína é amplamente usada em cosméticos devido à sua alta atividade biológica e capacidade de permear as camadas da pele, apesar de ser um composto hidrofílico. Este alcaloide é frequentemente utilizado como modelo hidrofílico de permeabilidade cutânea tanto em pele humana como animal e sintética através de sistemas de difusão tipo Franz. As formulações tópicas contendo cafeína são usadas no tratamento da celulite porque evitam o acúmulo de gordura excessiva nas células por estimular a lipólise. Além disso, a cafeína apresenta propriedades antioxidantes, o que protege a pele contra os efeitos danosos da radiação ultravioleta (UV) e retarda o processo de envelhecimento. ${ }^{23,24,25}$

Pires-de-Campos et al.4 estudaram o efeito de uma formulação em gel contendo $5 \%$ de cafeína associada ao ultrassom em hipoderme suína, durante 15 dias. Os resultados mostraram uma diminuição da espessura da hipoderme, com consequente redução do volume dos adipócitos. Velasco et al. ${ }^{5}$ também estudaram o efeito da cafeína em emulsão contendo alginato de siloxanetriol, aplicadas topicamente em camundongos fêmeas por 21 dias e verificaram uma 
redução no diâmetro das células adiposas, diminuição do efeito "casca de laranja" no macro relevo cutâneo e aumento da microcirculação cutânea.

O uso da fonoforese aumenta a permeação de substâncias ativas e fármacos através do aquecimento e energia do ultrassom, modificando a estrutura da camada córnea. ${ }^{13}$ Tassinary et al. ${ }^{26}$, avaliaram a permeação de uma formulação contendo 5\% de cafeína em hidrogel, com e sem a aplicação de ultrassom em membrana de cobra, utilizando sistema de difusão vertical. Os resultados demonstraram maior concentração de cafeína no ensaio com a aplicação de ultrassom $(30,194 \mathrm{mcg} / \mathrm{mL})$ e menor concentração no ensaio sem a aplicação do ultrassom (5,337 mcg/mL). Em nosso estudo, não foi possível detectar a presença de cafeína no ensaio de permeação em pele de porco sem a aplicação do ultrassom. Isso pode ter ocorrido devido à concentração de cafeína utilizada na formulação (1\%) e pelo tempo máximo de exposição (2 horas).

Na Figura 3 estão demonstrados os resultados do ensaio de retenção de substância ativa no estrato córneo, a partir da pele de porco, com e sem o uso do ultrassom. Em ambos os ensaios houve retenção e isso significa que os ativos ainda podem permear ao longo tempo, após a finalização do experimento. ${ }^{27}$

Observou-se que com o uso do ultrassom, a retenção foi menor em F2 e a permeação foi maior (Figura 2 e 3-A). Isso significa que, por permear mais através das camadas da pele, há uma menor retenção no estrato córneo. Entretanto, sem o uso do ultrassom, houve uma maior retenção (Figura 3-B). Neste caso, não foi observado permeação da cafeína, indicando que esse ativou ficou retido na camada córnea.

O principal mecanismo de regulação da permeação de moléculas por meio da pele está associado à matriz lipídica intercelular do estrato córneo, na forma de múltiplas lamelas, enquanto a matriz intracelular não contribui para a barreira difusora da pele. Assim, as regiões interlamelares contêm lipídios líquidos menos ordenados que são essenciais para a difusão transepidérmica de moléculas lipídicas e anfifílicas, uma vez que garantem o volume necessário para a migração. Pelo contrário, as moléculas hidrofílicas se difundem principalmente ao longo das superfícies das imperfeições interlamelares cheias de água (poros). ${ }^{28}$

A Tabela 4 apresenta o resultado qualitativo para a presença de saponinas triterpênicas nas formulações contendo extrato glicólico de Centella asiatica (F2 e F3). Observou-se que as saponinas triterpênicas da Centella asiatica foram identificadas no fluído receptor após a análise em luz UV, sendo que todas as formulações tiveram resultado positivo, inclusive ocorrendo permeação desse ativo sem o uso do ultrassom. Contudo, as formulações que foram aplicadas com o auxílio do ultrassom demonstraram manchas de coloração mais intensa na placa cromatográfica, indicando que o mesmo possibilita uma maior concentração dessas substâncias nas camadas mais profundas da pele.

Verificou-se que a Centella asiatica foi capaz de ultrapassar a membrana de acetato de celulose (cedência), permear a pele suína e ficar retida no estrato córneo, podendo ser identificada a partir de CCD. Com isso, nossos 
resultados parecem ser inéditos, uma vez que não há relatos na literatura científica sobre ensaios de permeação transepidermal a partir de formulações contendo Centella asiatica de forma isolada ou associada a outros ativos.

A Centella asiatica é usada no tratamento tópico da celulite nas concentrações de 2 a 5\%, atuando na melhora da microcirculação local e como agente anti-inflamatório. ${ }^{4}$ Seus constituintes biologicamente ativos fazem parte da classe dos triterpenos (metabólitos secundários), sendo os encontrados nessa espécie como compostos majoritários, o ácido asiático, ácido madecássico, asiaticoside e madecassoside, que são considerados os seus biomarcadores. ${ }^{7,9}$ Os constituintes químicos da Centella asiatica são bem conhecidos por seus efeitos no tratamento de doenças venosas crônicas e como cicatrizantes. ${ }^{8,29}$

Logo, a associação de cafeína com extrato glicólico de Centella asiatica parece ser uma combinação eficaz para o tratamento do FEG, uma vez que a formulação deve ter ativos capazes de atuar em todas as alterações provocadas por essa disfunção. Além disso, os ativos demonstraram apresentar uma permeação adequada com o uso do ultrassom. A retenção da camada córnea, observada em todas as formulações com e sem o uso do ultrassom, indicam que a permeação pode ocorrer gradualmente ao longo do tempo. Contudo, ressalta-se que seria importante realizar, em ensaios futuros, a quantificação dos compostos biotivos da Centella asiatica, o que consiste, no presente trabalho, de uma limitação do estudo.

\section{CONSIDERAÇÕES FINAIS}

O estudo possibilitou analisar a cedência, a permeação e a retenção cutânea de formulações cosméticas contendo cafeína e Centella asiatica, isoladas e associadas, através de sistema de difusão vertical. Baseando-se nos resultados expostos, conclui-se que os dois ativos cosméticos foram detectados nos ensaios de cedência, permeação e retenção. A permeação da cafeína somente foi observada com o uso do ultrassom, que consiste em um facilitador para a entrada dos ativos na pele. A retenção demostra que as substâncias ficaram retidas no estrato córneo e que, ao longo do tempo, podem ainda difundir-se através das demais camadas da pele.

\section{REFERÊNCIAS}

1. Oliveira DDG, Lima RS, Machado WPV, Gouvêa D, Abrahão P. Os benefícios da técnica de radiofrequência e a drenagem linfática manual na melhora do fibro edema gelóide (FEG). Ciência Atual. 2019;14(2):13-21.

2. Oliveira APA, Pires KS, Moreira JAR. A atuação da cafeína biovetorizada e do ultrassom no tratamento da lipodistrofia localizada na região abdominal: revisão literária. Medicina e Saúde. 2018;1(1):47-60. 
3. Marques NC, Soares JM, Guadanhim LRS, Sternberg F, Picosse FR, Yarak S et al. Does a Controlled Diet Improve Cellulite? Int J Nutr. 2013;2(1):25-37.

4. Pires-de-Campos MS, Leonardi GR, Chorilli M, Spadari-Bratfisch RC, Polacow MLO, Grassi-Kassisse DM. The effect of topical caffeine on the morphology of swine hypodermis as measured by ultrasound. J Cosmet Dermatol. 2008;7(3):232-7.

5. Velasco MVR, Tano CTN, Machado-Santelli GM, Consiglieri VO, Kaneko TM, Baby AR. Effects of caffeine and siloxanetriol alginate caffeine, as anticellulite agents, on fatty tissue: Histological evaluation. J Cosmet Dermatol. 2008;7(1):23-9.

6. Herman A, Herman AP. Caffeine's Mechanisms of Action and Its Cosmetic Use. Skin Pharmacol Physiol. 2013;26(1):8-14.

7. Zheng CJ, Qin LP. Chemical components of Centella asiatica and their bioactives. J Chin Integr Med. $2007 ; 5(3): 348-51$.

8. James JT, Dubery IA. Pentacyclic Triterpenoids from the Medicinal Herb, Centella asiatica (L.) Urban. Molecules. 2009;14(10):3922-41.

9. Rafamantanana MH, Rozet E, Raoelison GE, Cheuk, K, Ratsimamanga, SU, Hubert PH, et al. An improved HPLC-UV method for the simultaneous quantification of triterpenic glycosides and aglycones in leaves of Centella asiatica (L.) Urb (Apiaceae). J Chromatogr B. 2009;877(23):2396-402.

10. Alves NC. Penetração de ativos na pele: revisão bibliográfica. Revista Amazônia Science \& Health. 2015;3(4):36-43.

11. Soares M, Vitorino C, Sousa J, Pais A. Permeação cutânea: desafios e oportunidades. Rev Ciênc Farm Básica Apl. 2015;36(3):337-48.

12. Baby AR, Lacerda ACL, Pinto CASO, Lopes PS, Velasco MVR Kaneko TM. Métodos biofísicos empre- 
gados na análise do estrato córneo. Lat Am J Pharm. 2008;27(1):124-30.

13. Sinigaglia G, Bresciani L, Tassinary JAF, Périco E, Stülp S. Iontoforese associada ao princípio ativo ácido ascórbico: Avaliação de difusão vertical "in vitro". Scientia Plena. 2014;10(4):1-8.

14. Silva JA, Apolinário AC, Souza MSR, Damasceno BPGL, Medeiros ACD. Administração cutânea de fármacos: desafios e estratégias para o desenvolvimento de formulações transdérmicas. Rev Ciênc Farm Básica Apl. 2010;31(3):125-31.

15. Trommer $\mathrm{H}$, Neubert $\mathrm{RHH}$. Overcoming the stratum corneum: the modulation of skin penetration. Skin Pharmacol Physiol. 2006;19(2):106-21.

16. Mota ACV, Volpato NM, Freitas ZMF, Santos EP. Estudo de liberação in vitro do filtro solar p-metoxicinamato de octila incluso em lipossoma e [-ciclodextrina. Rev Ciênc Farm Básica Apl. 2008;29(3):285-9.

17. Megrab NA, Willians AC, Barry BW. Oestradiol permeation across human skin, silastic and snake skin membranes: the effects of ethanol/water co-solvent systems. Int J Pharm. 1995;116(1):101-12.

18. Li S, Berger J, Hartland S. UV spectrophotometric determination of theobromine and caffeine in cocoa beans. Anal Chim Acta. 1990;232(1):409-12.

19. Wagner H, Bladt S. PLant Drug Analysis. 2nd ed., Berlim. Springer-Verlag, 1996.

20. Kamel R, Mostafa DM. Rutin nanostructured lipid cosmeceutical preparation with sun protective potential. J Photoc Photobio B: Biology. 2015;153:59-66.

21. Kensy BS, Kerschnera KS, Costa DH, Deuschle VCKN. Permeação de substâncias ativas no fibro edema gelóide: revisão de literatura. Revista Biomotriz. 2019;13(3):70-80.

22. Mautari N. Experiência no uso do ultrassom focado no tratamento da gordura localizada em 120 pacientes. Surg Cosmet Dermatol. 2010;2(4):323-5. 
23. Rawlings AV. Cellulite and its treatment. Int J Cosmet Sci. 2006;28(3):175-90.

24. Cawthorn WP, Sethi JK. TNF- and adipocyte biology. FEBS Letters. 2008;582(1):117-31.

25. Trauer S, Lademann J, Knorr F, Richter H, Liebsch M, Rozycki C, et al. Development of an in vitro modified skin absorption test for the investigation of the follicular penetration pathway of caffeine. Skin Pharmacol Physiol. 2010;23(6):320-7.

26. Tassinary JA, Bianchetti P, Rempel C, Stülp, S. Avaliação dos efeitos do ultrassom terapêutico sobre a cafeína e verificação da liberação em sistema de difusão vertical. Quim Nova. 2011;34(9):1539-43.

27. Tassinary JÁ, Bresciani L, Bianchetti P, Rempel C, Schmitt B, Stülp S. Avaliação da permeação e da retenção da cafeína associada ao ultrassom terapêutico. Revista Destaques Acadêmicos. 2015;7(3):175-81.

28. Maretti E, Rustichelli C, Miselli P, Leo E, Truzzi E, lannuccelli V. Self-assembled organogelators as artificial stratum corneum models: Key-role parameters for skin permeation prediction. Int J Pharm. 2019;557(2019):314-28.

29. Rocha PBR, Souza BD, Andrade LM, Anjos JLV, Mendanha SA, Alonso A, et al. Enhanced asiaticoside skin permeation by Centella asiatica-loaded lipid nanoparticles: Effects of extract type and study of stratum corneum lipid dynamics. J Drug Deliv Sci Tec. 2019;50 (2019) 305-12 